\section{A) Check for updates}

Cite this: Polym. Chem., 2017, 8 , 4414

Received 24th May 2017

Accepted 29th June 2017

DOI: 10.1039/c7py00855d

rsc.li/polymers

\title{
Novel photoacid generators for cationic photopolymerization $\uparrow$
}

\author{
Nicolas Klikovits, (D) a Patrick Knaack, ${ }^{a}$ Daniel Bomze, ${ }^{a}$ Ingo Krossing (D) b and \\ Robert Liska iD *a
}

\begin{abstract}
Cationic photopolymerization is a powerful method for UV-curing of epoxy, vinyl ether and oxetane monomers. Little attention has been paid to it over the last few decades compared to the corresponding free radical applications due to unsuitable and inefficient photo-acid generators (PAGs) used for photoinitiation. We introduce a novel type of PAG based on the tetrakis(perfluoro-t-butyloxy)aluminate anion. In facile preparations, diphenyliodonium and triarylsulfonium salts were synthesized, followed by characterization of absorbance and thermal stability. Comparative photo-differential scanning calorimetry (photo-DSC) studies with common onium salt PAGs showed the advantageous reactivity of the novel alkoxyaluminate-based cationic photoinitiators. The novel diphenyliodonium PAG was also examined in photosensitization studies for potential use in higher wavelength applications.
\end{abstract}

\section{Introduction}

The great potential of photoinduced cationic polymerization was pointed out by Crivello in the early 1990s and subsequently also covered in many review articles. ${ }^{1-3}$ Cationic photopolymerization is applied most importantly for epoxy monomers, which offer special material properties such as excellent adhesion, mechanical strength and chemical resistance. These features cannot be attained by the predominant free radical photopolymerization and the corresponding monomers and they are mostly used for the production of adhesives, inks, films and coatings. ${ }^{4,5}$ Furthermore, vinyl ethers and oxetanes extend the applicability of cationic photopolymerization due to high reactivity, as well as environmental benefits and low toxicity, respectively. ${ }^{6-11}$

The advantages of cationic polymerization are high reaction rates, insensitivity towards oxygen and the huge variety of different polymer backbone structures. ${ }^{12}$ The practical absence of termination processes during polymerization ensures high efficiency in curing. One additional advantage of its use in industrial curing applications is the so-called "dark reaction". ${ }^{13-15}$ Once initiated, the relatively long-lived protonic acid, formed by the initiator, continues the polymerization also in the absence of light. As disadvantages one must

\footnotetext{
${ }^{a}$ Institute of Applied Synthetic Chemistry, TU-Wien, Vienna, Austria. E-mail: robert.liska@tuwien.ac.at

${ }^{b}$ Institute of Inorganic and Analytical Chemistry, University Freiburg, Freiburg, Germany

$\dagger$ Electronic supplementary information (ESI) available: Simultaneous thermal analysis (STA). See DOI: 10.1039/c7py00855d
}

mention the inhibition by bases, and chain transfer resulting from impurities of water. Still the cationic photopolymerization is a niche technique compared to the omnipresent free radical photopolymerization moreover due to the lack of efficient cationic photoinitiators.

Generally, cationic photopolymerization is initiated by photoacid generators (PAGs), which liberate carbo-cations and protons upon a light stimulus. Although there also exist nonionic PAGs, the onium salts, introduced by Crivello in the 1970s, ${ }^{6}$ represent the most efficient cationic photoinitiators to date. For this class of PAGs, Crivello assigned different roles to the cation and the anion part of the salt. ${ }^{1}$

Cations. The cation determines the photochemistry $\left(\lambda_{\max }\right.$, molecular absorption coefficient, quantum yield), thermal stability and usually also the photosensitization behaviour of the onium salt. As major classes of photoinitiators for cationic polymerization, diaryliodonium salts, ${ }^{6}$ triarylsulfonium salts, ${ }^{16}$ and also ferrocenium-based salts ${ }^{17}$ and diazonium salts ${ }^{18}$ were reported. The most widespread are diaryliodonium and triarylsulfonium salts because of their easy synthesis, their inherent thermal and storage stability even in highly reactive monomers, as well as their highly efficient photodecomposition.

Anions. The anions used for PAGs determine the strength of the acid formed upon photochemical decomposition of the onium cation. The kinetics of the polymerization is in direct relation to the non-nucleophilicity of the anion due to decreased ion-pairing. Low nucleophilicity and ion-pairing are provided by a series of weakly coordinating anions (WCA) developed over the last few decades. ${ }^{19,20}$ Superacid-forming perfluorinated compounds, such as $\mathrm{BF}_{4}{ }^{-}, \mathrm{PF}_{6}{ }^{-}, \mathrm{AsF}_{6}{ }^{-}$and $\mathrm{SbF}_{6}{ }^{-}$, are classically used anions for PAGs, of which hexafluoroanti- 


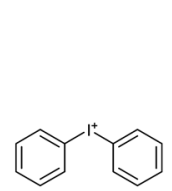

$1-$

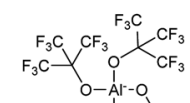

$$
\begin{aligned}
& \mathrm{F}_{3} \mathrm{C}-1 / \mathrm{CF}_{3}
\end{aligned}
$$$$
\mathrm{F}_{3} \mathrm{C} \underset{\mathrm{CF}_{3}}{\mathrm{~F}_{3} \mathrm{C} \quad \mathrm{CF}_{3}}
$$

-Al
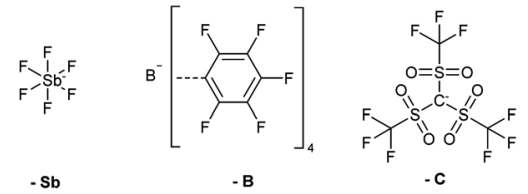

Fig. 1 Structures of cations and anions of novel and benchmark PAGs: diphenyliodonium (I-) and triarylsulfonium ( $\left.\mathrm{S}-, \mathrm{R}=\mathrm{S}-\mathrm{Ph}-\mathrm{COCH}_{3}\right)$ cations; tetrakis(perfluoro- $t$-butyloxy) aluminate (-Al), hexafluoroantimonate (-Sb), tetrakis(pentaflurophenyl)borate (-B) and tris((trifluoromethyl)sulfonyl)methanide (-C) anions.

monate exhibits the lowest nucleophilicity (Fig. 1, -Sb) ${ }^{1,21}$ As fluorine abstraction not only leads to termination processes during curing, but also to the formation of toxic hydrofluoric acid, the sensitivity of these compounds towards hydrolysis is a crucial issue. Also the content of toxic heavy metals such as antimony and arsenic greatly limits the applicability of these compounds as cationic photoinitiators.

Based on the preparation of perfluorinated alkylsulfonylmethanides by Turowsky et al. in the 1980s, the tris((trifluoromethyl)sulfonyl)methanide anion (Fig. 1, -C) was introduced as one of the strongest known carbon acids. ${ }^{22}$ Further investigations revealed that the strong Brønsted acidity was contributed by the delocalized nature of the charge in these anions. ${ }^{23}$ Furthermore, these anions provide improved solubility and subsequently found application in PAGs for the coating industry due to their enhanced resistance towards hydrolysis and liberation of hydrofluoric acid.

Castellanos et al. introduced the so-called BARF-anions $\left(\mathrm{BAr}_{4}^{\mathrm{F}}{ }_{4}^{-}\right)$in the 1990s (Fig. 1, -B), which promoted the development of a new generation of PAGs. ${ }^{24}$ This type of borate-based WCA is able to suppress strong cation-anion interactions by electronic shielding of the center ion with phenyl groups. Furthermore, high fluorination leads to the covering of the ion surface with poorly polarizable atoms. The combination of these properties causes improved solubility in even non-polar solvents and very low ion-pairing, approaching the requirements of an ideal anion for cationic photoinitiators. ${ }^{25}$ These borates, however, bear the disadvantage of difficult synthesis which cannot be up-scaled easily. The state-of-the-art synthesis of the most important tetrakis(pentafluorophenyl)borate makes usage of the, even at low temperatures, explosion-prone lithium pentafluorobenzene. ${ }^{26,27}$

Here we report a novel type of PAG for cationic photopolymerization based on the most recent class of WCAs, namely perfluorinated alkoxyaluminates. In the 1990s, preceding polyfluorinated alkoxyaluminate species, such as $\mathrm{Al}(\mathrm{OC}$ $\left.(\mathrm{Ph})\left(\mathrm{CF}_{3}\right)_{2}\right)_{4}{ }^{-}, \mathrm{Al}\left(\mathrm{OCH}\left(\mathrm{CF}_{3}\right)_{2}\right)_{4}{ }^{-}$, and $\mathrm{Al}\left(\mathrm{OC}\left(\mathrm{CH}_{3}\right)\left(\mathrm{CF}_{3}\right)_{2}\right)_{4}{ }^{-}$, were introduced with the most important aim to enhance the catalytic activity of metal cations. ${ }^{28,29}$ Krossing et al. firstly established the here covered perfluorinated alkoxyaluminate anion $\mathrm{Al}\left(\mathrm{OC}\left(\mathrm{CF}_{3}\right)_{3}\right)_{4}{ }^{-}$(Fig. 1, -Al), which provides outstandingly low nucleophilicity and ion-pairing, as well as high stability against hydrolysis, ligand abstraction and electrophilic decomposition. Empirically, the inherent stability of $\mathrm{Al}(\mathrm{OC}$ $\left.\left(\mathrm{CF}_{3}\right)_{3}\right)_{4}{ }^{-}$even in $6 \mathrm{~N} \mathrm{HNO}_{3}$ was confirmed. ${ }^{30}$ Resulting from basicity studies, this class of alkoxyaluminates has been found to exhibit their low nucleophilicity in correlation with the $\mathrm{p} K_{\mathrm{a}}$ value of the corresponding alcohol. ${ }^{31}$ Most significantly, the use of $\mathrm{Al}\left(\mathrm{OC}\left(\mathrm{CF}_{3}\right)_{3}\right)_{4}{ }^{-}$as the counterion in iridium-catalysts already showed enhanced reaction rates, in comparison to $\mathrm{BAr}^{\mathrm{F}}{ }_{4}^{-}$and $\mathrm{PF}_{6}{ }^{-32}$. Also the facile and easily up-scalable preparation of $\mathrm{LiAl}\left(\mathrm{OC}\left(\mathrm{CF}_{3}\right)_{3}\right)_{4}$ based on $\mathrm{LiAlH}_{4}$ and the corresponding alcohol was reported. ${ }^{30}$ Therefore, this superacidforming WCA was expected to provide excellent properties for use in PAGs.

As diaryliodonium and triarylsulfonium salts (Fig. 1, I- and $\mathbf{S}$-) are the most stable, most efficient and easiest to prepare cations with the highest abundance in industrial applications, these components were selected for the preparation of novel cationic photoinitiators. Diphenyliodonium and tris(4-((4-acetylphenyl)thio)phenyl)sulfonium salts of tetrakis(perfluoro-tbutyloxy)aluminate were prepared (Fig. 1, I-Al and S-Al) and subsequently investigated in comparative studies. The novel class of PAGs based on alkoxyaluminate was examined by UV-Vis spectroscopy, simultaneous thermal analysis (STA) and photo-DSC measurements to compare the reactivity to benchmark onium salts. The diphenyliodonium PAGs I-Al, I-B and $\mathbf{I - S b}$, as well as the triarylsulfonium PAGs S-Al, S-B and S-C were investigated.

\section{Experimental}

\section{Materials}

All reagents were purchased from Sigma-Aldrich, Fluka and ABCR and were used without further purification. Solvents were purchased and distilled prior usage. Thin Layer Chromatography (TLC) was carried out with silica gel 60 F254 aluminum foils from Merck. The monomers 2,2'-(((propane2,2-diylbis(4,1-phenylene))bis(oxy))bis(methylene))bis(oxirane) (BADGE; Araldite MY 790-1, Huntsman) and 1,4-bis(((3-ethyloxetan-3-yl)methoxy)methyl)benzene (BOB, Ivoclar Vivadent) were kindly provided as a gift. The monomers 4-cyclohexanedimethanol divinylether (BVC, ABCR), 2-(phenoxymethyl)oxirane (PGE, Fluka), and 1-(vinyloxy)dodecane (DVE, Sigma-Aldrich) and the sensitizer 2-isopropylthioxanthone (ITX, Speedcure, Lambson) were purchased and used as received. The monomer 3-(butoxymethyl)-3-ethyloxetane (BEO) was synthesized according to the literature. ${ }^{33}$ 
The photoinitiators tris(4-((4-acetylphenyl)thio)phenyl)sulfonium tetrakis(perfluorophenyl)borate (Irgacure PAG290, S-B) and tris(4-((4-acetylphenyl)thio)phenyl)sulfonium tris((trifluoromethyl)sulfonyl)methanide (Irgacure GSID-26-1, S-C) were kindly donated by BASF. Diphenyliodonium hexafluoroantimonate (I-Sb) and diphenyliodonium tetrakis(perfluorophenyl)borate (I-B) were synthesized according to the literature. ${ }^{6,24}$

\section{Synthesis}

Diphenyliodonium tetrakis(perfluoro-t-butyloxy)aluminate. The synthesis was conducted in an orange light room under an argon atmosphere. In a $1000 \mathrm{~mL}$ 3-necked round bottom flask equipped with a reflux condenser, a septum, a glass fitting and a magnetic stirring bar, $14.28 \mathrm{~g}(14.66 \mathrm{mmol}, 1.0$ eq.) of lithium tetrakis(perfluoro-t-butyloxy)aluminate were dispersed in $320 \mathrm{~mL}$ of $\mathrm{CH}_{2} \mathrm{Cl}_{2}$. A solution of $4.64 \mathrm{~g}$ (14.66 mmol, 1.0 eq.) of diphenyliodonium chloride in $230 \mathrm{~mL}$ of $\mathrm{CH}_{2} \mathrm{Cl}_{2}$ was added slowly. The immediate precipitation of a white solid was observed. Another $180 \mathrm{~mL}$ of $\mathrm{CH}_{2} \mathrm{Cl}_{2}$ were added and the reaction was stirred overnight at room temperature. Even after 24 hours of reaction control by TLC, no total conversion of the educts was observed, so an excess of $5 \%$ of diphenyliodonium chloride $(0.23 \mathrm{~g}, 0.73 \mathrm{mmol})$ was added. After another hour of stirring, $350 \mathrm{~mL}$ of deionized water were added to dissolve the solid. The phases were separated and the organic phase was extracted another two times with $350 \mathrm{~mL}$ of deionized water each. To separate the residual starting materials from the product, the combined organic phases were filtered through a short plug of silica. The solvent was evaporated in vacuo and the residue was dried under a high vacuum yielding $15.66 \mathrm{~g}$ (12.56 mmol, 85\%) of a white solid. $\mathrm{Mp}$ 172-174 ${ }^{\circ} \mathrm{C}$. TLC $\left(\mathrm{CH}_{2} \mathrm{Cl}_{2}\right): R_{\mathrm{f}}=0.41 .{ }^{1} \mathrm{H}-\mathrm{NMR}(400 \mathrm{MHz}$, $\left.\mathrm{CD}_{2} \mathrm{Cl}_{2}\right) \delta(\mathrm{ppm}): 7.94-8.03(\mathrm{~m}, 2 \mathrm{H}), 7.79-7.89(\mathrm{~m}, 1 \mathrm{H})$, 7.58-7.70 (m, 2H). ${ }^{13} \mathrm{C}-\mathrm{NMR}\left(100 \mathrm{MHz}, \mathrm{CD}_{2} \mathrm{Cl}_{2}\right) \delta(\mathrm{ppm}): 111.8$ (C-I), 121.7 (q, C( $\left.\left.\underline{C F}_{3}\right), J=291.5 \mathrm{~Hz}\right), 134.4(\mathrm{~m}), 135.1$ (p), 135.5 (o). ${ }^{27} \mathrm{Al}-\mathrm{NMR}\left(104 \mathrm{MHz}, \mathrm{CD}_{2} \mathrm{Cl}_{2}\right) \delta$ (ppm): 34.7. ATR-IR: 1470, 1449, 1351, 1296, 1273, 1239, 1205, 1165, 966, 831, 735, 724, 673, 548, 571, 560, $536 \mathrm{~cm}^{-1}$. Elem. anal. calcd: C 26.94\%, H $0.81 \%$, F $54.79 \%$, I $10.17 \%$. Found: C $27.19 \%$, H $0.82 \%$, F $53.04 \%$, I $9.86 \%$.

Tris(4-((4-acetylphenyl)thio)phenyl)sulfonium tetrakis(perfluoro-t-butyloxy)aluminate. The synthesis was conducted in an orange light room under an argon atmosphere. In a $20 \mathrm{~mL}$ test tube equipped with a septum and a magnetic stirring bar and closed by a metal lid, $77 \mathrm{mg}(0.08 \mathrm{mmol}, 1.0$ eq. $)$ lithium tetrakis(perfluoro-t-butyloxy)aluminate were dissolved in $9 \mathrm{~mL}$ of $\mathrm{CH}_{2} \mathrm{Cl}_{2}$. A solution of $60 \mathrm{mg}(0.08 \mathrm{mmol}, 1.0$ eq. $)$ of tris(4((4-acetylphenyl)thio)phenyl)sulfonium chloride in $3 \mathrm{~mL}$ of $\mathrm{CH}_{2} \mathrm{Cl}_{2}$ was added dropwise under vigorous stirring. The immediate precipitation of a white solid was observed. The reaction mixture was stirred overnight and the conversion was checked by TLC. $5 \mathrm{~mL}$ of deionized water were added to dissolve the solid and the organic phase was extracted another two times with $5 \mathrm{~mL}$ of deionized water each. To separate the residual starting materials from the product, the combined organic phases were filtered through a short plug of silica. The solvent was evaporated in vacuo and the residue was dried under a high vacuum yielding $106 \mathrm{mg}(0.06 \mathrm{mmol}, 80 \%)$ of a white solid. Mp 174-176 ${ }^{\circ} \mathrm{C}$. TLC $\left(\mathrm{CH}_{2} \mathrm{Cl}_{2}\right): R_{\mathrm{f}}=0.15 .{ }^{1} \mathrm{H}-\mathrm{NMR}$ $\left(400 \mathrm{MHz}, \mathrm{CDCl}_{3}\right) \delta(\mathrm{ppm}): 8.00(\mathrm{~d}, 6 \mathrm{H}, J=8.60 \mathrm{~Hz}, \mathrm{Ar}), 7.59$ (d, 6H, $J=8.60 \mathrm{~Hz}, \mathrm{Ar}$ ), 7.34 (d, 6H, $J=8.56 \mathrm{~Hz}, \mathrm{Ar}$ ), 7.26 (d, $6 \mathrm{H}, J=9.00 \mathrm{~Hz}, \mathrm{Ar}$ ), 2.62 (s, 9H, $\mathrm{CH}_{3}$ ). ATR-IR: 1685, 1572, 1478, 1398, 1352, 1298, 1276, 1239, 1213, 1166, 1089, 1067, 972, 814, 727, $620 \mathrm{~cm}^{-1}$. Elem. anal. calcd: C 41.44\%, H $1.98 \%$, S 7.63\%. Found: C $41.77 \%$, H 1.91\%, S 7.38\%.

\section{Characterization}

${ }^{1} \mathrm{H}$ and ${ }^{13} \mathrm{C}$ NMR spectra were recorded on a Bruker Avance $400 \mathrm{MHz}$ FT-NMR-spectrometer. Deuterated chloroform $\left(\mathrm{CDCl}_{3}\right)$ and dichloromethane $\left(\mathrm{CD}_{2} \mathrm{Cl}_{2}\right)$ were used as solvent. FTIR-ATR spectra were recorded on a Spectrum 65 FTIR-ATR spectroscope from PerkinElmer. Melting points were determined with an OptiMelt automated melting point system from SRS Stanford Research Systems. Elemental microanalysis was carried out with an EA 1108 CHNS-O analyzer from Carlo Erba at the microanalytical laboratory of the Institute for Physical Chemistry at the University of Vienna.

UV-Vis spectroscopy. For UV-Vis spectrometry, the photoinitiators I-Al, I-B and I-Sb were dissolved in methanol, and S-Al, S-B and S-C were dissolved in acetonitrile, respectively, under light protection (orange light room). From stock solutions of $1 \times 10^{-4} \mathrm{~mol} \mathrm{~L}^{-1}$, dilutions of $5 \times 10^{-5} \mathrm{~mol} \mathrm{~L}^{-1}$ and $1 \times 10^{-5}$ mol L ${ }^{-1}$ were prepared. The measurements were performed using a Lambda 950 device from PerkinElmer equipped with a PMT detector for the UV/Vis area. Quartz cuvettes were used for all measurements.

Thermal analysis. For STA measurements, about $4 \mathrm{mg}$ of the cationic photoinitiators were weighed into standard aluminium DSC crucibles and closed with appropriate aluminium lids. A STA 449 F1 Jupiter from Netzsch was used. All analyses were performed at a heating rate of $20^{\circ} \mathrm{C} \mathrm{min}{ }^{-1}$ from $25{ }^{\circ} \mathrm{C}$ to $300 \mathrm{C}^{\circ}$ under air.

\section{Photo-DSC}

Photo-DSC studies were conducted with a photo-DSC 204 F1 from Netzsch. Filtered UV-Vis light (320-500 nm, 400-500 nm) was applied using an Omnicure 2000 in combination with a glassfiber filled double-core lightguide (3 $\mathrm{mm}$ fiber diameter). For comparative studies, the light intensity was measured by using an Omnicure R2000 radiometer and set to $1 \mathrm{~W} \mathrm{~cm}^{-2}$ or $3 \mathrm{~W} \mathrm{~cm} \mathrm{~cm}^{-2}$ at the tip of the light guide, respectively. All measurements were conducted under an inert atmosphere (nitrogen flow of $20 \mathrm{~mL} \mathrm{~min}{ }^{-1}$ ). The measurements were carried out in isothermal mode at $50{ }^{\circ} \mathrm{C}$. The heat flow of the reaction was recorded as a function of time.

Formulations of $1 \mathrm{~mol} \%$ of the PAGs in BADGE, BOB and BVC were prepared for comparative photo-DSC studies of cationic photoinitiators in difunctional monomers. The formulations were weighed into $3 \mathrm{~mL}$ brown glass vials and subsequently stirred magnetically for 2 hours. After this time, the initiator has been dissolved completely. The triarylsulfonium 
photoinitiators could not be dissolved in the divinylether BVC, so 25 molar equivalents of propylene carbonate were added to all mixtures. For sensitization experiments, ITX was mixed with BADGE in concentrations of $0.01,0.05$ and $0.1 \mathrm{~mol} \%$, followed by analogous sample preparation with $1 \mathrm{~mol} \%$ of diphenyliodonium PAGs.

The sample mass in the aluminium crucibles was $14 \pm$ $0.5 \mathrm{mg}$. All measurements were performed in triplicate. Important data for the determination of the conversion ( $C_{\text {photo-DSC }}$ ), the time to reach $95 \%$ of conversion $\left(t_{95}\right)$, and the rate of polymerization $\left(R_{\mathrm{p}}\right)$ are the molecular weight, density and the theoretical enthalpy per mol of the functional group $\left(\Delta H_{0 \mathrm{P}}\right)$ of the monomer. To determine the enthalpies $\Delta H_{0 \mathrm{P}}$ of the different functional groups, photo-DSC and ${ }^{1} \mathrm{H}-\mathrm{NMR}$ of structurally analogous monofunctional monomers of BADGE, BOB and BVC were carried out. On the assumption that the polymerization enthalpy per reactive group is equal for monofunctional and difunctional monomers, the theoretical polymerization enthalpies $\Delta H_{0 \mathrm{P}}$ for $100 \%$ conversion could be calculated according to eqn (1), where $\Delta H_{\mathrm{P}}$ is the overall heat evolved in photo-DSC analysis, $C_{\mathrm{NMR}}$ is the conversion determined by ${ }^{1} \mathrm{H}-\mathrm{NMR}, m_{\mathrm{tot}}$ is the total mass of the formulation, MW is the molecular weight and $m$ is the mass of the monomer.

Calculation of theoretical functional group enthalpy $\Delta H_{\mathrm{OP}}$.

$$
\Delta H_{0 \mathrm{P}}=\frac{\Delta H_{\mathrm{P}} \times \mathrm{MW}}{\frac{m}{m_{\mathrm{tot}}} \times C_{\mathrm{NMR}}}
$$

\section{Results and discussion}

\section{Synthesis}

The synthesis of the novel photoinitiators comprising the tetrakis(perfluoro-t-butyloxy)aluminate, I-Al and S-Al, was conducted in simple metathesis reactions in analogy to the already reported preparations of onium salts. ${ }^{6}$ The ion exchange was performed using the chloride salts of the cations and the lithium tetrakis(perfluoro-t-butyloxy)aluminate as the anion source (Fig. 2). With the precipitation of lithium chlor-

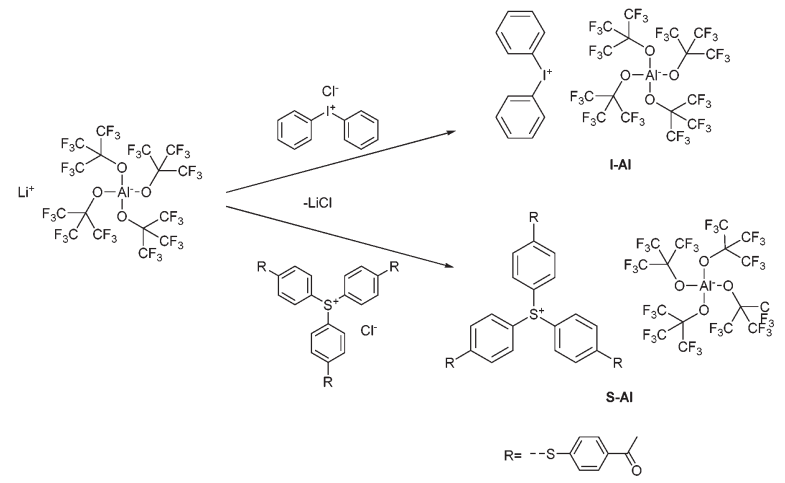

Fig. 2 Synthesis of novel diphenyliodonium and triarylsulfonium PAGs. ide, the products were obtained in dichloromethane solution and purified by extraction with water and filtration over silica. No further purification of the metathesis products was necessary. The purity was confirmed by TLC and elementary analysis and the products were obtained in good yields of $85 \%$ for I-Al, and $80 \%$ for S-Al, respectively.

\section{UV-Vis spectroscopy}

UV-Vis absorption spectra were obtained from $1 \times 10^{-4} \mathrm{~mol} \mathrm{~L}^{-1}$, $5 \times 10^{-5} \mathrm{~mol} \mathrm{~L}^{-1}$ and $1 \times 10^{-5} \mathrm{~mol} \mathrm{~L}^{-1}$ of the PAGs in methanol (diphenyliodonium salts) and acetonitrile (triarylsulfonium salts). By these measurements, the wavelengths of absorption maxima $\left(\lambda_{\max }\right)$ as well as molar extinction coefficients $(\varepsilon)$ were determined. As the diphenyliodonium and triarylsulfonium cations contain the chromophores, no differences in absorption were expected for photoinitiators comprising the same cation. It was confirmed that the novel WCA has no influence on the absorption behaviour of the initiators. Only for the borate-based PAGs, I-B and $\mathbf{S - B}$, the expected increase of absorption in far UV was observed due to the phenyl substituents. For diphenyliodonium PAGs, an absorption maximum at $227 \mathrm{~nm}\left(\varepsilon_{227}=17800 \mathrm{~L} \mathrm{~mol}^{-1} \mathrm{~cm}^{-1}\right)$ was determined, whereas the substituted triarylsulfonium PAGs exhibit a local absorption maximum at $318 \mathrm{~nm}\left(\varepsilon_{318}=60900 \mathrm{~L} \mathrm{~mol}^{-1} \mathrm{~cm}^{-1}\right)$ (Fig. 3).

\section{Simultaneous thermal analysis}

Simultaneous thermal analysis (STA), comprising thermogravimetric analysis (TGA) and differential scanning calorimetry (DSC), was used to determine the thermal stability of the new PAGs. The solid photoinitiator samples were heated to $300{ }^{\circ} \mathrm{C}$. Thereby, mass losses and phase transitions during heating can be followed simultaneously from one sample. The analysis showed a thermal stability until $220{ }^{\circ} \mathrm{C}$ for all three diphenyliodonium PAGs. The triarylsulfonium PAGs did not decompose within the measurement range until $300{ }^{\circ} \mathrm{C}$, thus confirming the high thermal stability formerly reported. ${ }^{1}$

\section{Photo-DSC studies for the effect of anion nature on photochemical reactivity}

Photo-DSC is a unique method for obtaining a fast and accurate indication of the PAG performance. With a single measurement, various significant parameters are accessible. From the height of the exothermic peak, the $R_{\mathrm{p}}\left(\mathrm{mol} \mathrm{L} \mathrm{L}^{-1} \mathrm{~s}^{-1}\right)$ can be calculated as described in earlier publications of this
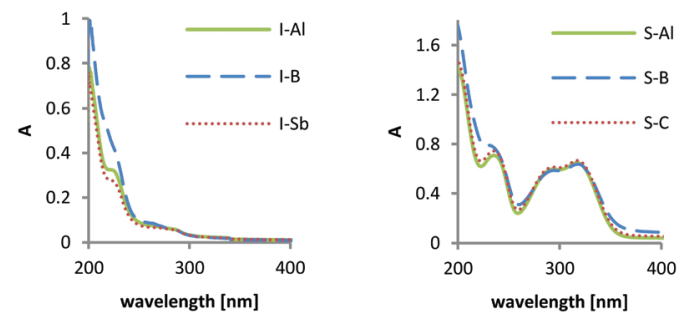

Fig. 3 Absorption spectra of diphenyliodonium and triarylsulfonium PAGs. 
group. ${ }^{34}$ The overall heat evolved $\left(\Delta H_{\mathrm{P}}\right)$ serves as a measure of the total conversion, which is also the basis for the determination of the time of $95 \%$ conversion $\left(t_{95}\right)$.

Selection of cationically polymerizable monomers. As the reactivity of the compared PAGs may depend on the type of polymerizable group, photo-DSC studies were carried out in three difunctional monomers comprising the most important functionalities, namely glycidylether, oxetane and vinyl ether. Therefore, the diepoxide BADGE, the dioxetane BOB and the divinylether BVC (Fig. 4) were used in these studies, as they represent the most common classes of cationically polymerizable monomers. To determine the theoretical polymerization enthalpies $\Delta H_{0 \mathrm{P}}$ for these functional groups, monofunctional monomers were first investigated in preceding measurements. On the assumption that the enthalpy per reactive group is equal for analogous monofunctional and difunctional monomers, the monofunctional glycidylether PGE, the 1,3-disubstituted oxetane BEO and the vinyl ether DVE were used (Fig. 4). ${ }^{1} \mathrm{H}-\mathrm{NMR}$ analyses of samples cured in photo-DSC experiments ( $1 \mathrm{~W} \mathrm{~cm}^{-2}$ irradiation intensity) with the novel PAG I-Al were used to calculate $\Delta H_{\mathrm{OP}}$ of each functional group based on the $\Delta H_{\mathrm{P}}$ (photo-DSC) and the corresponding conversion $\left(C_{\mathrm{NMR}}\right)$ (eqn (1), Table 1$)$.

Deviation of these photocalorimetric results from commonly cited literature values (e.g. phenyl glycidyl ether, lit. $92 \mathrm{~kJ} \mathrm{~mol}^{-1} ;^{35}$ 3,3-disubstituted oxetane, lit. $84 \mathrm{~kJ} \mathrm{~mol}^{-1} ;^{36,37}$ vinyl ether, lit. $60 \mathrm{~kJ} \mathrm{~mol}^{-1}$ (ref. 37 and 38)) is reasoned by the dependence on the method of determination, such as combustion, calorimetry or calculation. Still the results were reproducible under the set conditions and thus considered as representative measures for further evaluations.

Comparative analysis of diphenyliodonium initiators. The novel photoinitiator I-Al and the benchmark photoinitiators

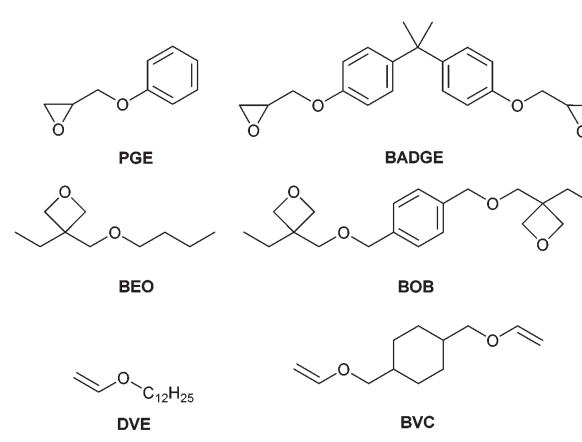

Fig. 4 Monofunctional and difunctional monomers for photo-DSC studies.

Table 1 Molecular weight (MW), molar functional group enthalpy $\left(\Delta H_{\mathrm{OP}}\right)$ and density $(\rho)$ of difunctional monomers

\begin{tabular}{lllc}
\hline Monomers & $\mathrm{MW}\left[\mathrm{g} \mathrm{mol}^{-1}\right]$ & $\Delta H_{\mathrm{OP}}\left[\mathrm{kJ} \mathrm{mol}^{-1}\right]$ & $\rho\left[\mathrm{g} \mathrm{L}^{-1}\right]$ \\
\hline BADGE & 340.42 & 80.6 & 1160 \\
BOB & 334.46 & 83.6 & 1070 \\
BVC & 196.29 & 75.0 & 920
\end{tabular}

$\mathbf{I}-\mathbf{B}$ and $\mathbf{I - S b}$ were tested in three difunctional monomers BADGE, BOB and BVC in a concentration of $1 \mathrm{~mol} \%$ (corresponding to $0.5 \mathrm{~mol} \%$ per reactive group as for monofunctional monomers). The irradiation intensity was chosen to be $3 \mathrm{~W} \mathrm{~cm}^{-2}$ at the tip of the light guide. The high reactivity of the divinylether BVC did not allow for a measurement at high energy input as it led to exceeding the detector limit. Thus, it was analyzed at $1 \mathrm{~W} \mathrm{~cm}^{-2}$ instead. As a typical example, Fig. 5 shows the conversion curves of the tested diphenyliodonium PAGs in BADGE. The benefits of the novel I-Al are apparent and are also displayed in Table 2 in detail. The comparison in BADGE shows a clearly advantageous initiation ability and polymerization behaviour of the novel I-Al in the majority of tests. In particular, $R_{\mathrm{P}}$ is greatly increased for $\mathbf{I}-\mathbf{A l}$, whereas $t_{95}$ is decreased in comparison to the benchmark PAGs in BADGE formulations. As the rate of polymerization $\left(R_{\mathrm{P}}\right)$ displays the most representative result parameter for reactivity, it is seen that I-Al exhibits 1.4 times higher $R_{\mathrm{P}}$ in BADGE, compared to both benchmark PAGs. In the dioxetane BOB also significant benefits are apparent in the parameters $R_{\mathrm{P}}$ and $t_{95}$, whereas the conversion generally reaches around $70 \%$ for all diphenyliodonium PAGs. In BOB, a ranking is displayed where I-Al has $7 \%$ higher $R_{\mathrm{P}}$ than $\mathbf{I}-\mathbf{B}$, and $15 \%$ higher $R_{\mathrm{P}}$ than $\mathbf{I}-\mathbf{S b}$. Only the highly reactive divinylether $\mathbf{B V C}$ exhibits extraordinarily high $R_{\mathrm{P}}$, low $t_{95}$ values and increased conversions of over $80 \%$ for all tested PAGs. I-Al reaches the same order of reactivity as I-Sb, which is 5\% lower than I-B.

Comparative analysis of triarylsulfonium initiators. In analogy to the diphenyliodonium photoinitiators, the substituted triarylsulfonium species were compared with each other within a photo-DSC measurement sequence. The novel PAG S-Al was compared with commercially available high-performance photoinitiators S-B and S-C in the monomers BADGE, BOB and BVC in a concentration of $1 \mathrm{~mol} \%$. Also the triarylsulfonium photoinitiators were tested with an irradiation intensity of $3 \mathrm{~W} \mathrm{~cm}^{-2}$ at the tip of the light guide, and $1 \mathrm{~W} \mathrm{~cm}^{-2}$ for BVC. Fig. 6 shows the typical conversion curves of the tested triarylsulfonium PAGs in BADGE. In contrast to diphenyliodonium PAGs in BADGE (Fig. 5), one can see the rapid and steep increase of conversion at the beginning of irradiation. This is reasoned by the better overlap of the absorption bands of the triarylsulfonium cation (S-) and the emission provided by the light source (320-500 $\mathrm{nm})$.

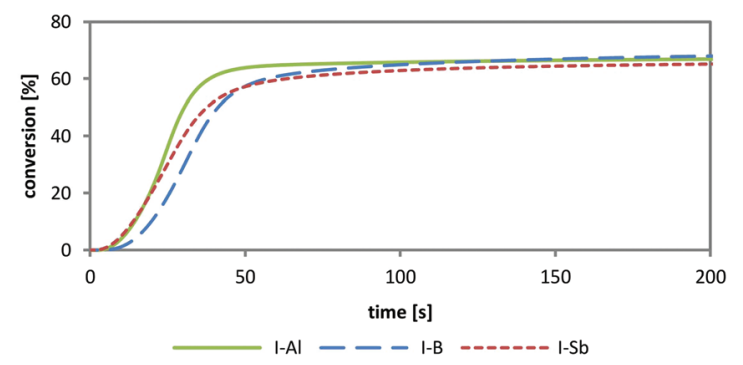

Fig. 5 Comparative photo-DSC conversion curves of diphenyliodonium PAGs (1 mol\%) in BADGE. 
Table 2 Photo-DSC result parameters of diphenyliodonium and triarylsulfonium PAGs (1 mol\%) in BADGE, BOB and BVC

\begin{tabular}{|c|c|c|c|c|c|c|c|c|c|}
\hline Monomer & \multicolumn{3}{|c|}{$R_{\mathrm{p}}\left[\mathrm{mmol} \mathrm{L} \mathrm{L}^{-1} \mathrm{~s}^{-1}\right]$} & \multicolumn{3}{|l|}{$t_{95}[\mathrm{~s}]$} & \multicolumn{3}{|c|}{$C_{\text {photo-DSC }}[\%]$} \\
\hline I-Al & 108 & 178 & 517 & 56 & 46 & 24 & 70 & 73 & 84 \\
\hline I-B & 73 & 166 & 543 & 134 & 50 & 24 & 72 & 73 & 88 \\
\hline I-Sb & 76 & 155 & 516 & 98 & 50 & 24 & 69 & 71 & 78 \\
\hline S-Al & 49 & 43 & 134 & 240 & 307 & 52 & 64 & 72 & 68 \\
\hline
\end{tabular}

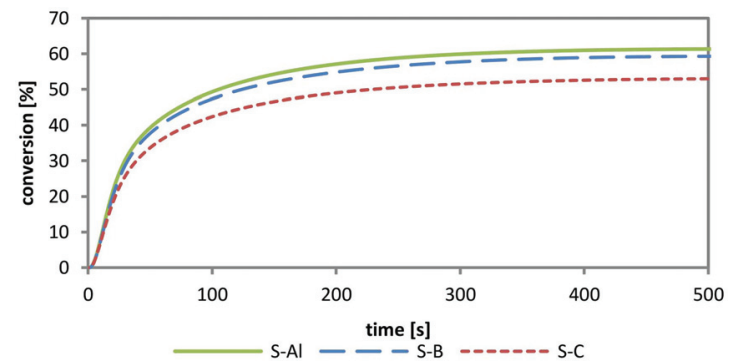

Fig. 6 Comparative photo-DSC conversion curves of triarylsulfonium PAGs (1 mol\%) in BADGE.

The results in Table 2 show only marginal differences between the PAGs in the three monomers. The novel S-Al matches up to the provided triarylsulfonium high-performance initiators. No clear trend is achieved and the results show only dependence on the respective monomer. The overall deviations allow no prediction on the advantageous behaviour of any of the PAGs, making them equally potent cationic photoinitiators under these conditions.

Comparative analysis of diphenyliodonium with higher wavelength sensitization. Cationic UV-curing is usually initiated using UV lamps that provide radiation in the near UV region above $350 \mathrm{~nm}$, thus exceeding the absorption regions of common PAGs. To meet the requirements of industrial light sources, much effort has been put into the development of visible light photoinitiators over the past few years. The application of visible light LEDs further pushes the investigation on new solutions to this issue. To enable the use of common PAGs with higher wavelength radiation sources, the absorption properties of the photosensitive formulation have to be changed. The recent research focused on the development to redshift the absorption by enlarged $\pi$-conjugated systems and was applied mostly on sulfonium salts. ${ }^{39-43}$ For diphenyliodonium salts, however, the predominant approach for visible light applications is the use of photosensitization. Sensitizers absorb the light energy in their specific absorption range in the visible region. By the dominant electron transfer mechanism, the cationic photoinitiator initiates the polymerization without being directly excited. Iodonium salts are generally more easily sensitized due to their rather high redox potential $(-0.2 \mathrm{eV})$, whereas sulfonium salts are only sensitized by com- pounds with high singlet energies, such as anthracenes, due to the low redox potential $(-1.2 \mathrm{eV}) .{ }^{12}$ Thus, photosensitization is still considered as a current method for diphenyliodonium PAGs and was examined here.

The typical sensitizer 2-isopropylthioxanthone (ITX) was selected for the comparison of alkoxyaluminate- and antimonate-based diphenyliodonium initiators in BADGE formulations. Fig. 7 depicts the low overlap of diphenyliodonium species with the emission of an Omnicure 2000 UV lamp and the well-fitting absorption of the used sensitizer. A concentration of $1.0 \mathrm{~mol} \%$ PAG was used in combination with concentrations of $0.01,0.05$ and $0.1 \mathrm{~mol} \%$ of ITX. Photo-DSC measurements with $400-500 \mathrm{~nm}$ irradiation with $3 \mathrm{~W} \mathrm{~cm}^{-2}$ intensity were performed to investigate the differences in the sensitization ability of the novel initiator I-Al compared to the benchmark compound I-Sb. At this wavelength, hardly any reaction was observed for diphenyliodonium salts without the sensitizer. However, with the use of ITX the cationic photopolymerization of BADGE was facilitated distinctively.

Considering that the sensitization process is determined by the cation of the PAGs, the measurement depicts the overall ability to effectively generate an acid after photodecomposition. Thus, a different reactivity is contributed by the acid forming WCA after photosensitization. The sensitization by ITX enables the activation of both tested diphenyliodonium PAGs in a BADGE matrix. Using the lowest concentration of $0.01 \mathrm{~mol} \%$ ITX, generally sluggish polymerization was observed with low $R_{\mathrm{p}}$, long $t_{95}$ times and low conversions. The aluminate based PAG I-Al still shows better results under these conditions. A higher concentration of $0.1 \mathrm{~mol} \%$ causes

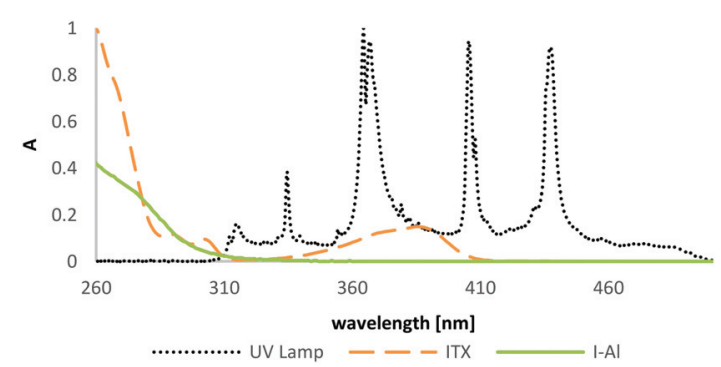

Fig. 7 Emission spectrum of an Omnicure 2000 series UV lamp; absorption spectra of sensitizers ITX and diphenyliodonium PAG I-Al. 


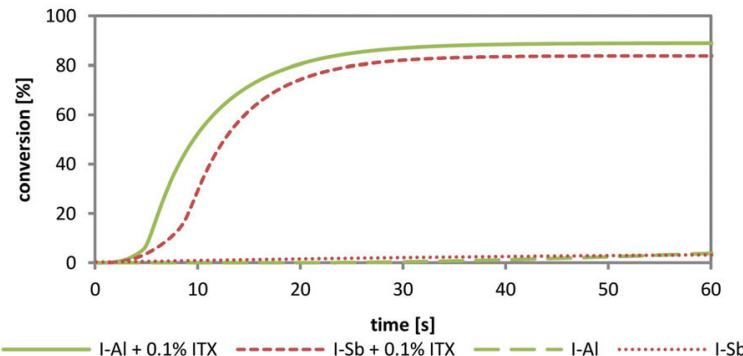

Fig. 8 Comparative photo-DSC conversion curves of I-Al and I-Sb (1 mol\%) in BADGE with ITX sensitization (0.1 mol\%) at 400-500 nm.

Table 3 Polymerization parameters of diphenyliodonium photoinitiators (1 mol\%) in BADGE with ITX-sensitization

\begin{tabular}{lllll}
\hline Photoinitiator & $\begin{array}{l}\text { ITX } \\
{[\mathrm{mol} \%]}\end{array}$ & $\begin{array}{l}R_{\mathrm{p}} \\
{\left[\mathrm{mmol} \mathrm{L}^{-1} \mathrm{~s}^{-1}\right]}\end{array}$ & $t_{95}[\mathrm{~s}]$ & $\begin{array}{l}C_{\text {photo-DSC }} \\
{[\%]}\end{array}$ \\
\hline I-Al & 0.01 & 0.011 & 316 & 59 \\
I-Sb & & 0.010 & 347 & 55 \\
I-Al & 0.10 & 0.393 & 30 & 92 \\
I-Sb & & 0.344 & 30 & 85 \\
\end{tabular}

distinctively more efficient polymerization behaviour with the novel I-Al. The beneficial reactivity is also displayed in the typical conversion curve in Fig. 8. From the result parameters in Table 3, it can be seen that the highest final conversions are reached by the novel PAG I-Al.

\section{Conclusions}

In this paper, the preparation and investigation of a novel class of cationic photoinitiators is shown. The synthesis of two new compounds, I-Al and S-Al, was performed by straightforward metathesis reactions based on lithium tetrakis(perfluoro-t-butyloxy)aluminate in $85 \%$ and $80 \%$ yield, respectively. In preceding studies it was confirmed that the absorbance and thermal stability of the onium salts are not affected by the novel anion, and shows equal properties to benchmark substances, including expectedly beneficial results for the triarylsulfonium PAG S-Al. Photo-DSC studies revealed the superior reactivity in comparison to benchmark substances in several monomers. In particular, the diphenyliodonium species I-Al demonstrates a greatly advantageous ability to initiate cationic polymerization, where the efficient photopolymerization of the usually low reactive BADGE is of prime importance. Also the photosensitization experiments of I-Al using ITX showed convincing results in comparison to the benchmark substance, which demonstrates the possible usage in photoinitiators systems with visible light irradiation. On the one hand, the novel photoinitiators provide enhanced reactivity for classical use in the coating industry, on the other hand, the novel class of PAGs offers access to new applications, where reactivity and stability are the limiting factors to date.

\section{Acknowledgements}

This work was funded by the Austrian Government and the state Governments of Styria, Lower- and Upper Austria within the FFG PolyComp project (project number: 836647). The authors acknowledge the TU Wien University Library for financial support through its Open Access Funding Program.

\section{Notes and references}

1 J. V. Crivello, J. Polym. Sci., Part A: Polym. Chem., 1999, 37, 4241-4254.

2 J. V. Crivello, Des. Monomers Polym., 2002, 5, 141154.

3 M. Sangermano, Pure Appl. Chem., 2012, 84, 2089.

4 H. Q. Pham and M. J. Marks, in Ullmann's Encyclopedia of Industrial Chemistry, Wiley-VCH Verlag GmbH \& Co. KGaA, 2000, DOI: 10.1002/14356007.a09_547.pub2.

5 W. A. Green, Industrial Photoinitiators: A Technical Guide, Taylor \& Francis, 2010.

6 J. V. Crivello and J. H. W. Lam, Macromolecules, 1977, 10, 1307-1315.

7 M. Sangermano, G. Malucelli, F. Morel, C. Decker and A. Priola, Eur. Polym. J., 1999, 35, 639-645.

8 C. Decker, C. Bianchi, D. Decker and F. Morel, Prog. Org. Coat., 2001, 42, 253-256.

9 Y.-M. Kim, L. K. Kostanski and J. F. MacGregor, Polym. Eng. Sci., 2005, 45, 1546-1555.

10 U. Bulut and J. V. Crivello, J. Polym. Sci., Part A: Polym. Chem., 2005, 43, 3205-3220.

11 M. Sangermano, G. Malucelli, R. Bongiovanni and A. Priola, Eur. Polym. J., 2004, 40, 353-358.

12 J. V. Crivello, K. Dietliker and G. Bradley, Photoinitiators for Free Radical Cationic \& Anionic Photopolymerisation, Wiley, 1999.

13 V. Sipani and A. B. Scranton, J. Polym. Sci., Part A: Polym. Chem., 2003, 41, 2064-2072.

14 C. Decker and K. Moussa, J. Polym. Sci., Part A: Polym. Chem., 1990, 28, 3429-3443.

15 H. Ito, N. Kidokoro and H. Ishikawa, J. Photopolym. Sci. Technol., 1992, 5, 235-246.

16 J. V. Crivello and J. H. W. Lam, J. Polym. Sci., Polym. Chem. Ed., 1979, 17, 977-999.

17 A. Roloff, K. Meier and M. Riediker, Pure Appl. Chem., 1986, 58, 1267.

18 S. I. Schlesinger, Polym. Eng. Sci., 1974, 14, 513-515.

19 T. A. Engesser, M. R. Lichtenthaler, M. Schleep and I. Krossing, Chem. Soc. Rev., 2016, 45, 789-899.

20 I. Krossing and I. Raabe, Angew. Chem., Int. Ed., 2004, 43, 2066-2090.

21 G. A. Olah, G. K. S. Prakash and J. Sommer, Superacids, Wiley, 1985.

22 L. Turowsky and K. Seppelt, Inorg. Chem., 1988, 27, 21352137. 
23 S. Z. Zhu and D. D. DesMarteau, Inorg. Chem., 1993, 32, 223-226.

24 F. Castellanos, J. P. Fouassier, C. Priou and J. Cavezzan, J. Appl. Polym. Sci., 1996, 60, 705-713.

25 I. Krossing, in Comprehensive Inorganic Chemistry II, ed. K. Poeppelmeier, Elsevier, Amsterdam, 2nd edn, 2013, pp. 681-705, DOI: 10.1016/B978-0-08-097774-4.00126-1.

26 A. G. Massey and A. J. Park, J. Organomet. Chem., 1964, 2, 245-250.

27 Y. Ikeda, T. Yamane, E. Kaji and K. Ishimaru, US Pat., 5493056 (A), 1996.

28 T. J. Barbarich, S. T. Handy, S. M. Miller, O. P. Anderson, P. A. Grieco and S. H. Strauss, Organometallics, 1996, 15, 3776-3778.

29 T. J. Barbarich, S. M. Miller, O. P. Anderson and S. H. Strauss, J. Mol. Catal. A: Chem., 1998, 128, 289-331.

30 I. Krossing, Chem. - Eur. J., 2001, 7, 490-502.

31 S. M. Ivanova, B. G. Nolan, Y. Kobayashi, S. M. Miller, O. P. Anderson and S. H. Strauss, Chem. - Eur. J., 2001, 7, 503-510.

32 S. P. Smidt, N. Zimmermann, M. Studer and A. Pfaltz, Chem. - Eur. J., 2004, 10, 4685-4693.

33 T. Matsumoto and H. Mazaki, US Pat., 2004173773 (A1), 2004.
34 G. Ullrich, B. Ganster, U. Salz, N. Moszner and R. Liska, J. Polym. Sci., Part A: Polym. Chem., 2006, 44, 1686-1700.

35 C. H. Klute and W. Viehmann, J. Appl. Polym. Sci., 1961, 5, 86-95.

36 F. S. Dainton, K. J. Ivin and D. A. G. Walmsley, Trans. Faraday Soc., 1960, 56, 1784-1792.

37 J. Brandrup, E. H. Immergut and E. A. Grulke, Polymer Handbook, Wiley, 4th edn, 1999.

38 M. F. Shostakovskii and I. F. Bogdanov, Russ. J. Appl. Chem., 1942, 15, 249-259.

39 X. Wu, J.-p. Malval, D. Wan and M. Jin, Dyes Pigm., 2016, 132, 128-135.

40 M. Jin, X. Wu, J. Xie, J. P. Malval and D. Wan, RSC Adv., 2015, 5, 55340-55347.

41 M. Jin, H. Hong, J. Xie, J.-P. Malval, A. Spangenberg, O. Soppera, D. Wan, H. Pu, D.-L. Versace, T. Leclerc, P. Baldeck, O. Poizat and S. Knopf, Polym. Chem., 2014, 5, 4747-4755.

42 M. Jin, H. Xu, H. Hong, J.-P. Malval, Y. Zhang, A. Ren, D. Wan and H. Pu, Chem. Commun., 2013, 49, 8480-8482.

43 W. Zhou, S. M. Kuebler, K. L. Braun, T. Yu, J. K. Cammack, C. K. Ober, J. W. Perry and S. R. Marder, Science, 2002, 296, 1106-1109. 